\title{
ERRATA
}

\section{Rapid Radiometric Method for Detection of Salmonella in Foods}

\author{
BETTY J. STEWART, MICHAEL J. EYLES, AND WILLIAM G. MURRELL
}

Commonwealth Scientific and Industrial Research Organization, Division of Food Research, North Ryde, New South Wales, Australia

Volume 40, number 2, page 223, column 2, line 10: "surface plating on brain heart agar" should read "surface plating on brain heart infusion agar."

Page 225, column 1, line 2 from bottom: " $>1.5: 1$ " should read " $\geq 1.5: 1$."

Page 225, column 2, lines 5 and 6: "no effect on metabolism growth, or both, Salmonella" should read "no effect on metabolism or growth, or both, of Salmonella."

Page 226, column 1, paragraph 1, line 9: "count for 24 h" should read "count after 24 h."

Page 229-230, column 2, last line: The sentence beginning "The major cost factor" should read "The major cost factor in the use of this radiometric method is the necessity for a radioactivity counter. Automation of this measurement is feasible with an instrument such as the Bactec model 301 instrument..."

\section{Virulence Prediction of Yersinia enterocolitica by Pyrolysis Gas-Liquid Chromatography}

\author{
NORMAN J. STERN, A. W. KOTULA, AND M. D. PIERSON
}

Meat Science Research Laboratory, U. S. Department of Agriculture, Beltsville, Maryland 20705, and Department of Food Science and Technology, Virginia Polytechnic Institute and State University, Blacksburg, Virginia 24061

Volume 40, number 3, page 648, legend to Fig. 1: The legend should read "Y. enterocolitica strain $C D C$ A2635 invading HeLa cells $(B)$. Uninoculated HeLa cell culture $(A)$. " 